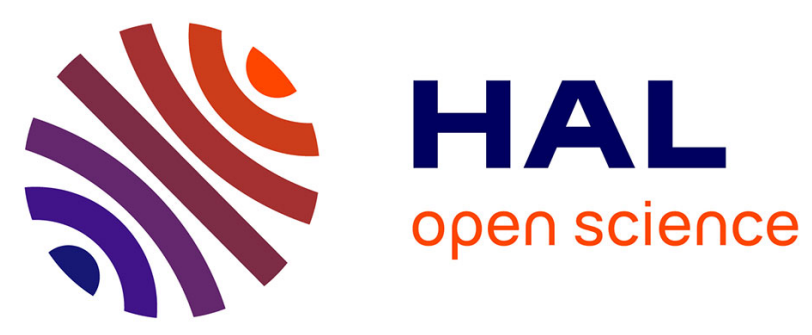

\title{
Gestational stress and fluoxetine treatment differentially affect plasticity, methylation and serotonin levels in the PFC and hippocampus of rat dams
}

\author{
Mary Gemmel, Ine Rayen, Eva Van Donkelaar, Tiffany Loftus, Harry W \\ Steinbusch, Nikolaos Kokras, Christina Dalla, Jodi L Pawluski
}

\section{To cite this version:}

Mary Gemmel, Ine Rayen, Eva Van Donkelaar, Tiffany Loftus, Harry W Steinbusch, et al.. Gestational stress and fluoxetine treatment differentially affect plasticity, methylation and serotonin levels in the PFC and hippocampus of rat dams. Neuroscience, 2016, 327, pp.32-43. 10.1016/j.neuroscience.2016.03.068 . hal-01301509

HAL Id: hal-01301509

https://hal-univ-rennes1.archives-ouvertes.fr/hal-01301509

Submitted on 8 Sep 2016

HAL is a multi-disciplinary open access archive for the deposit and dissemination of scientific research documents, whether they are published or not. The documents may come from teaching and research institutions in France or abroad, or from public or private research centers.
L'archive ouverte pluridisciplinaire HAL, est destinée au dépôt et à la diffusion de documents scientifiques de niveau recherche, publiés ou non, émanant des établissements d'enseignement et de recherche français ou étrangers, des laboratoires publics ou privés. 


\section{Running head: Maternal stress, SSRIs and Neurobiology}

Gestational stress and fluoxetine treatment differentially affect plasticity, methylation and serotonin levels in the PFC and hippocampus of rat dams

Mary Gemmel ${ }^{1}$, Ine Rayen ${ }^{2}$, Eva van Donkelaar ${ }^{2}$, Tiffany Loftus ${ }^{1}$, Harry W Steinbusch ${ }^{2}$, Nikolaos Kokras ${ }^{3}$, Christina Dalla ${ }^{3}$ and Jodi L. Pawluski ${ }^{1,2,4 *}$,

${ }^{1}$ Department of Biological Sciences, Ohio University, Athens, Ohio, USA

${ }^{2}$ Department of Neuroscience, Maastricht University, Netherlands

${ }^{3}$ Department of Pharmacology, Medical School, University of Athens, Greece

${ }^{4}$ IRSET INSERM UMR1085, University of Rennes 1, France,

*Corresponding Author: Jodi L. Pawluski, Ph.D.,

Université de Rennes 1, Campus Villejean, 9 avenue du Prof. Leon Bernard, 35000 Rennes

FRANCE, Phone: +33(0)2 23.23.41.90, Email address: j.pawluski@gmail.com / jodi.pawluski@univ-rennes1.fr

Acknowledgements: The authors report no conflict of interest. JLP was funded by a Charge de recherche position from the F.R.S.-FNRS in Belgium and is presently funded by a Brain \& Behavior Foundation NARSAD Young Investigator Grant. 


\begin{abstract}
Women are more likely to develop depression during childbearing years with up to $20 \%$ of women suffering from depression during pregnancy and in the postpartum period. Increased prevalence of depression during the perinatal period has resulted in frequent selective serotonin reuptake inhibitor (SSRI) antidepressant treatment; however the effects of such medications on the maternal brain remain limited. Therefore, the aim of the present study is to investigate the effects of the SSRI medication, fluoxetine, on neurobiological differences in the maternal brain. To model aspects of maternal depression, gestational stress was used. Sprague-Dawley rat dams were exposed to either gestational stress and/or fluoxetine $(5 \mathrm{mg} / \mathrm{kg} /$ day $)$ to form the following four groups: 1. Control+Vehicle, 2. Stress+Vehicle, 3. Control+Fluoxetine 4. Stress+Fluoxetine. At weaning maternal brains were collected. Main findings show that gestational stress alone increased synaptophysin and serotonin metabolism in the CG2 region of the cortex while fluoxetine treatment after stress normalized these effects. In the hippocampus, fluoxetine treatment, regardless of gestational stress exposure, decreased both global measures of methylation in the dentate gyrus, as measured by Dnmt3a immunoreactivity, as well as serotonin metabolism. No further changes in synaptophysin, PSD-95, or Dnmt3a immunoreactivity were seen in the cortical or hippocampal areas investigated. These findings show that gestational stress and SSRI medication affect the neurobiology of the maternal brain in a region-specific manner. This work adds to a much needed area of research aimed at understanding neurobiological changes associated with maternal depression and the role of SSRI treatment in altering these changes in the female brain.
\end{abstract}

Keywords: antidepressant medication; female; neurotransmitters; postpartum depression; neuroplasticity; SSRI 


\section{INTRODUCTION}

The peripartum period is a time when women are at an increased risk of developing stress-related disorders, such as depression and anxiety. For example, diagnosis rates estimate that $20 \%$ of pregnant and postpartum women suffer from depression (Bennett et al., 2004). There are a number of risk factors for developing depression during the perinatal period which include, but are not limited to, stressful life events, a history of depression or anxiety, lacking social support, unplanned pregnancy, and being of lower socio-economic status (Lancaster et al., 2010; Stewart, 2011). Consequentially, such risk factors contribute to maternal stress, depression, or anxiety during gestation and in the postpartum period, and may result in poor physical and mental infant development (Huizink et al., 2003; Oberlander et al., 2009; Talge et al., 2007); including impairments in cognitive abilities and increased risk to develop neuropsychiatric disorders (Beversdorf et al., 2005; Huizink et al., 2004; Huizink et al., 2003; Laplante et al., 2004; Niederhofer and Reiter, 2004; Van den Bergh et al., 2005; Van den Bergh et al., 2008). In animals models, stress before conception, during the prenatal period, or the postnatal period can significantly affect offspring development on a number of domains from behavioral performance, physiology, neural plasticity and the epigenome (Darnaudery and Maccari, 2008; Glover et al., 2009; Huang et al., 2013; Huang et al., 2010; Huang et al., 2012; Maccari and Morley-Fletcher, 2007; Van den Hove et al., 2005; Weinstock, 2007).

Although there is a large body of research investigating the impact of maternal stress and maternal depression on offspring development, more research is needed to understand how maternal stress and stress-related disorders affects neurobiological outcomes in the mother. In humans, there are changes in many brain areas of women with affective symptoms and postpartum depression (for review see (Moses-Kolko et al., 2014). Animal models of maternal stress and/or depression, which use repeated stress exposure or administration of corticosterone during the perinatal period (Brummelte and Galea, 2010; Darnaudery et al., 2004; Hillerer et al., 2011; Leuner et al., 2014; O'Mahony et al., 2006; Pawluski et al., 2012c; Pawluski et al., 2011; Smith et al., 2004), are beginning to show the extent to which maternal stress can remodel the maternal brain. For example, animal studies show that repeated restraint stress during pregnancy, or exogenous corticosterone administration, alters hippocampal neurogenesis, dendritic morphology and other measures of plasticity in the maternal brain during the peripartum period 
(Brummelte and Galea, 2010; Hillerer et al., 2014; Maghsoudi et al., 2014; Pawluski et al., 2015; Pawluski et al., 2012c; Pawluski et al., 2011; Workman et al., 2013). Gestational stress can also have a long term impact on the maternal brain by abolishing the enduring increase in hippocampal LTP months after giving birth (Lemaire et al., 2006).

As with major depression, maternal stress and depression is associated with changes in maternal monoamine system functioning (Kohl et al., 2005; Veen et al., 2016) which plays an important role in motherhood (Angoa-Perez et al., 2014; Curry et al., 2013; Davies et al., 2015; Keer and Stern, 1999; Stamatakis et al., 2015; Vicentic et al., 2006). Recent work shows that pup separation reduces 5-HT1A receptor levels in the hippocampus of mother rats, thereby showing a role for the serotonergic system in maternal care and maternal stress (Stamatakis et al., 2015). Furthermore, 5 months after gestational stress, 5-HT1A receptor levels are reduced in the PFC and hippocampus of rat dams (Szewczyk et al., 2014). Yet little is known about how maternal stress may alter central monoamine systems in the maternal brain.

Due to the role of the hippocampus in depression, stress, and anxiety, much of the neurobiological research on maternal stress and depression has focused on this brain region. However, recent work in animal models is showing how maternal stress, as a model of aspects of maternal depression, may affect plasticity in other brain areas, such as the prefrontal cortex (PFC) and nucleus accumbens (Haim et al., 2014; Leuner et al., 2014): brain areas which also play a role in depression. Leuner et al (2014) report that repeated gestational stress, as a model of postpartum depression, results in decreased spine density and alterations in dendritic spine morphology of pyramidal neurons in the medial prefrontal cortex of rat dams during the postpartum period. Others have shown that repeated stress during gestation results in decreased maternal care during the postpartum period (Smith et al., 2004) and altered glucocorticoid levels in dams (Hillerer et al., 2011). However, further research is needed to understand the complex neurobiological and brain-region specific changes that occur with maternal stress and maternal mood disorders.

Because of the significant effect of maternal stress-related mood disorders on the mother and child, a growing number of women are being treated with selective serotonin reuptake inhibitor medications (SSRIs) during the peripartum period (Cooper et al., 2007; Fleschler and Peskin, 2007; Ververs et al., 2006). SSRIs can act to alleviate depressive symptoms in adults by 
normalizing serotonin function, and regulating the HPA axis (Barden et al., 1995), hippocampal plasticity (Malberg and Duman, 2003; Santarelli et al., 2003) and methylation (Hunter et al., 2009). Unfortunately very little is known about the effects of SSRIs on neurobiology and methylation changes in the maternal brain. Understanding changes in maternal neurobiology, specifically changes in global methylation, may indicate brain regions which are sensitive to gene expression variability following SSRI treatment during the peripartum period. Recent research shows that SSRIs can enhance hippocampal neurogenesis (Pawluski et al., 2012a) and reverse the effects of gestational stress on synaptic morphology in the medial PFC (Haim et al., 2015). However, it remains to be determined how SSRI exposure affects monoaminergic systems and other measures of plasticity and methylation throughout the maternal brain.

The aim of the current study was to investigate how gestational stress, to model aspects of maternal depression (Gemmel et al., 2015; Leuner et al., 2014; O'Mahony et al., 2006; Smith et al., 2004), affects brain region specific neuroplasticity, global changes in methylation, and monoamine systems in the hippocampus and PFC of postpartum rat dams. The study also aimed to determine how fluoxetine, a popular SSRI used during the perinatal period (Mitchell et al., 2011), may alter any neurobiological effects of maternal stress on the maternal brain. It is expected that maternal gestational stress will alter plasticity and monoamine functioning, and that SSRI treatment may ameliorate these stress effects. This work contributes to an important area of research aimed at understanding the maternal brain and improving maternal mental health.

\section{METHODS}

Animals. Twenty-two adult female Sprague-Dawley rats $(250-300$ g; Charles River Laboratories, Saint-Germain-Nuelles France) were used. Ten adult male Sprague-Dawley rats (300-350 g; Charles River Laboratories, Saint-Germain-Nuelles France) were used for breeding. Rats were initially housed in pairs in clear polyutherane bins under standard laboratory conditions with a $12 \mathrm{~h}: 12 \mathrm{~h}$ light/dark schedule (lights on at $0700 \mathrm{~h}$ ) and ad libitum access to rat chow (Sniff) and tap water. Experiments were approved by the Animal Ethics Board of Maastricht University in accordance with governmental regulations of the Netherlands (DEC 
2010-150). All efforts were made to minimize pain and stress levels experienced by the animals, as well as the number of animals used.

Breeding was completed by placing 1 female and 1 male together in a wire mesh cage with the day of vaginal plug release determined as gestational day (GD) 1. Dams were randomly assigned to stress $(n=11)$ or control conditions $(n=11)$ on GD15. Dams in the stress condition were subject to restraint three times each day for 45 minutes in transparent plastic cylinders under bright light (at a random point between 8 and 10 a.m., 12 and 2 p.m., and 4 and 6 p.m.). This was carried out on GD 15-20 and twice a day (at a random time point between 8 and 10 a.m., 12 and 2 p.m.) on GD21 (Rayen et al., 2015; Rayen et al., 2013). Dams were further assigned to one of two treatment groups: fluoxetine $(5 \mathrm{mg} / \mathrm{kg} / \mathrm{day})$ or vehicle for a total of four groups of dams: 1) Control + Vehicle (Control) (n=6), 2) Stress + Vehicle (Stress) ( $n=5)$, 3) Control+Fluoxetine (Fluox) (n=5) 4) Stress + Fluoxetine (Stress+Fluox) (n=6). At weaning (Postpartum day 21), brains of dams were collected ( $n=5-6 /$ group). Litters were culled to 5 male and 5 female pups when possible. Offspring were used in additional studies (Gemmel et al., 2015; Rayen et al., 2015; Rayen et al., 2013, 2014).

Fluoxetine treatment. Dams were exposed to 4 weeks of fluoxetine treatment via osmotic minipumps (Alzet Osmotic pumps, 2ML4, Charles River, Eindhoven, The Netherlands), which result in appropriate fluoxetine serum levels (Pawluski et al., 2012b; Rayen et al., 2011). Minipumps were implanted subcutaneously in the dorsal region of the dam on postpartum day 1 using isofluorane anesthesia. Minipumps were filled with either fluoxetine $(5 \mathrm{mg} / \mathrm{kg} / \mathrm{day}$; Fagron, Belgium) dissolved in vehicle (50\% propylenediol in saline) or with vehicle. Osmotic minipumps were used instead of repeated injections or oral gavage to minimize the effect of repeated stress on the mother and offspring. Implants took a maximum of 20 minutes. We have consistently found that minipumps do release fluoxetine, and its active metabolie norfluoxetine, at expected levels (Pawluski et al., 2012a; Pawluski et al., 2014).

Histology. At weaning, dams were deeply anaesthetized (sodium pentobarbital), weighed, and brains were extracted. Brains were halved along the midline and the hippocampus and prefrontal area of the cortex were quickly dissected from the right hemisphere of the brain, weighed, fresh frozen on dry ice, and used to assess dopamine (DA), dopamine's metabolite dihyroxyphenylacetic acid (DOPAC), homovanillic acid (HVA) levels, dopamine turnover ratios 
(DOPAC/DA and HVA/DA), serotonin (5-HT), serotonin's metabolite, 5-hydroxyindoleacetic acid (5-HIAA) levels and serotonin turnover ratios (5-HIAA/5-HT) $(n=4-6)$. The left hemisphere was immersion-fixed in $4 \%$ paraformaldehyde for $24 \mathrm{~h}$, cryoprotected in $30 \%$ sucrose/phosphate-buffered saline solution for up to 1 week, stored in brain antifreeze solution (supersaturated .01 M PBS, polyvinyl pyrrolidone and ethylene glycol sucrose solution) and kept at $-20^{\circ} \mathrm{C}$ until further use. Minimal work has shown lateralization differences in monoamine functioning, particularly in the rat hippocampus (Andersen and Teicher, 1999). However, some work has indicated monoamine and metabolite lateralization differences in the female cortex (Molodtsova, 2001). To control for any effect of lateralization, the left hemisphere was always utilized for immunohistochemical techniques, and the right hemisphere was assessed for monoamine changes.

Immunohistochemistry. The left hemisphere was sliced in $40 \mu \mathrm{m}$ slices on a cryostat resulting in 12 serial wells (Leica Biosystems, Buffalo Grove, IL, USA) (n=5-6/group). Tissue wells were stored in antifreeze solution and maintained at $-20^{\circ} \mathrm{C}$.

DCX staining. For doublecortin (DCX) staining, sections were rinsed between steps in TBS and TBST. Tissue for DCX quantification was incubated in $0.6 \% \mathrm{H}_{2} \mathrm{O}_{2}$ at room temperature for 30 minutes followed by overnight incubation at $4^{\circ} \mathrm{C}$ in goat anti-doublecortin (1:200, Santa Cruz Biotechnology, Dallas Texas, USA). Sections were then incubated at room temperature for $2 \mathrm{~h}$ in biotinylated rabbit anti-goat (1:500, Vector laboratories, Burlingame, CA, USA). The tissue was further processed using the avidine-biotine complex (ABC Elite kit; 1:1000; Vector laboratories, Burlingame, CA, USA) and DAB + Nickel (3,3-diaminobenzidine; Vector laboratories, Burlingame, CA, USA). Sections were mounted on Superfrost Plus slides (Fischer Scientific, Pittsburgh, PA), dried, dehydrated and cover-slipped with Permount (Fischer Scientific, Pittsburgh, PA).

For quantification, the number of DCX immunoreactive cells (-ir) cells were counted under 40x objective (Rayen et al., 2015). Cells were counted throughout the GCL/SGZ on every $6^{\text {th }}$ hippocampi. Cells were considered DCX-ir if they were darkly stained with the presence of dendritic processes. For representative photomicrographs see Figure 1A.

Synaptophysin staining. For synaptophysin staining, sections were rinsed between steps in TBS and TBST. Tissue was first blocked with 5\% Normal Goat Serum (Lampire Biological 
Laboratories, Pipersville PA, USA) in TBST at room temperature for 30 minutes followed by overnight incubation at $4^{\circ} \mathrm{C}$ in mouse anti-synaptophysin (1:200, Sigma Aldrich, St. Louis MO, USA). Sections were then incubated at room temperature for $2 \mathrm{~h}$ in biotinylated goat anti-mouse (1:500, Vector laboratories, Burlingame, CA, USA). Tissue was further processed using the avidine-biotine complex (ABC Elite kit; 1:1000; Vector laboratories, Burlingame, CA, USA) and DAB + Nickel (3,3-diaminobenzidine; Vector, Burlingame, CA, USA). Sections were mounted on Superfrost Plus slides (Fischer Scientific, Pittsburgh, PA), dried, dehydrated and coverslipped with Permount (Fischer Scientific, Pittsburgh, PA).

PSD-95 staining. For PSD-95 staining, sections were rinsed between steps in TBS and TBST. Tissue was first subjected to antigen unmasking with $10 \mathrm{mM}$ sodium citrate buffer $(\mathrm{pH}$ 6.0) in a water bath for $20 \mathrm{~min}$ at $80^{\circ} \mathrm{C}$, then incubated with $0.6 \%$ hydrogen peroxide for 30 minutes at room temperature to quench endogenous peroxidase activity. Tissue was blocked with 2\% Normal Goat Serum (NGS) (Lampire Biological Laboratories Pipersville PA, USA) in TBST. Sections were then incubated in rabbit anti-PSD-95 (1:1000, abcam, Cambridge MA, USA) for 1 hour at room temperature, followed by overnight incubation at $4{ }^{\circ} \mathrm{C}$. Sections were then incubated for $2 \mathrm{~h}$ at room temperature in biotinylated goat anti-rabbit (1:500, Vector laboratories, Burlingame, CA, USA). Further processing of the tissue was completed using the avidine-biotine complex (ABC Elite kit; 1:1000; Vector laboratories, Burlingame, CA, USA) and DAB + Nickel (3,3-diaminobenzidine; Vector, Burlingame, CA, USA). Sections were mounted on Superfrost Plus slides (Fischer Scientific, Pittsburgh, PA), dried, dehydrated and coverslipped with Permount (Fischer Scientific, Pittsburgh, PA).

Dnmt3a staining. For Dnmt3a staining, sections were rinsed between steps in TBS and TBST. Tissue for Dnmt3a quantification was first subjected to antigen unmasking with $10 \mathrm{mM}$ sodium citrate buffer $\left(\mathrm{pH} 6.0\right.$ ) in a water bath for $20 \mathrm{~min}$ at $80^{\circ} \mathrm{C}$, then incubated with $0.6 \%$ hydrogen peroxide for 30 minutes at room temperature to quench endogenous peroxidase activity. Tissue was blocked with 2\% Normal Goat Serum (NGS) (Lampire Biological Laboratories Pipersville PA, USA) in TBST for $1 \mathrm{~h}$ at room temperature followed by incubation in rabbit polyclonal anti-Dnmt3a in 2\% NGS+TBST (1:200, Santa Cruz Biotechnology, Dallas Texas, USA) at room temperature for $1 \mathrm{~h}$, then overnight at $4^{\circ} \mathrm{C}$. Sections were then incubated for $2 \mathrm{~h}$ at room temperature in biotinylated goat anti-rabbit in TBST (1:500, Vector laboratories, 
Burlingame, CA, USA). The tissue was further processed using the avidine-biotine complex (ABC Elite kit; 1:400; Vector laboratories, Burlingame, CA, USA) and DAB + Nickel (3,3diaminobenzidine; Vector laboratories, Burlingame, CA, USA). Sections were mounted on Superfrost Plus slides (Fischer Scientific, Pittsburgh, PA), dried, dehydrated and cover-slipped with Permount (Fischer Scientific, Pittsburgh, PA).

Quantification. For quantification of synaptophysin, PSD-95, and Dnmt3a immunoreactivity, two sections, from a series of every $12^{\text {th }}$ slice, of the PFC located between stereotaxic coordinates bregma $+3 \mathrm{~mm}$ to $+2.5 \mathrm{~mm}$ in the infralimbic cortex (IL) and cingulate cortex (CG) regions and two dorsal sections of the hippocampus located between stereotaxic coordinates bregma $-2.64 \mathrm{~mm}$ to $-4.92 \mathrm{~mm}$ were analyzed based on previous work (Gemmel et al., 2015; Hammels et al., 2015; Pawluski et al., 2014; Rayen et al., 2015). Photomicrographs were taken for two areas within the CA3 and GCL/SGZ of the hippocampus from each of the sections, for four areas within the CG (two areas each from CG3 and CG2) and for two areas within the IL from each of the two sections. Immunoreactivity for all sections was examined under 40x objective using a Nikon Microphot SA and Nikon DS-Qi1MC camera with Nikon NIS Elements F4.00 software. Quantification of optical densities was completed using ImageJ64 (Wayne Rasband, NIH, Bethesda MD, USA) for synaptophysin immunoreactive (ir) cells, PSD95-ir cells, and Dnmt3a-ir cells. The difference between optical density (grey level) after calibration within the area of interest and in an equivalent adjacent area (background) was defined as the relative optical density. For representative photomicrographs of synaptophysin density, PSD-95 density and Dnmt3a density see Figure 1B-D respectively.

Neurochemical Measurements. High performance liquid chromatography with electrochemical detection (HPLC-ED) was used to measure monoamine levels. Dissected tissues were weighed, homogenized and deproteinized in $0.1 \mathrm{~N}$ perchloric acid solution (Applichem, Darmstadt, Germany) containing 7.9 $\mathrm{mM} \mathrm{Na}_{2} \mathrm{~S}_{2} \mathrm{O}_{5}$ and $1.3 \mathrm{mM} \mathrm{Na} 2$ EDTA (Riedel-de Haën AG, Seelze, Germany), centrifuged at $20000 \mathrm{~g}$ for $45 \mathrm{~min}$ at $4{ }^{\circ} \mathrm{C}$ and the supernatant was stored at $80^{\circ} \mathrm{C}$ until analysis. Analysis was performed using a GBC LC1150 HPLC pump (GBC Scientific Equipment, Braeside, Victoria, Australia) coupled with a BAS-LC-4C (Bioanalytical Systems Inc., West Lafayette, IN, USA) electrochemical detector (Kokras et al., 2009; Kyratsas et al., 2013). The working electrode of the electrochemical detector was set at $+800 \mathrm{mV}$. Reverse phase 
ion pairing chromatography was used to assay dopamine (DA) and its metabolites 3,4 dihydroxyphenylacetate (DOPAC) and homovanillic acid (HVA), serotonin (5-HT) and its metabolite 5-hydroxyindoleatic (5-HIAA), and norepinephrine (NE) in all samples. The mobile phase consisted of a $50 \mathrm{mM}$ phosphate buffer regulated at $\mathrm{pH} 3.0$, containing 5-octylsulfate sodium salt at a concentration of $300 \mathrm{mg} / \mathrm{L}$ as the ion pairing reagent and $\mathrm{Na}_{2} \mathrm{EDTA}$ at a concentratio of $20 \mathrm{mg} / \mathrm{L}$ (Riedel-de Haën AG); acetonitrile (Merck, Darmstadt, Germany) was added at a $8-15 \%$ concentratio. The reference standards were prepared in $0.1 \mathrm{~N}$ perchloric acid solution containing $7.9 \mathrm{mM} \mathrm{Na}_{2} \mathrm{~S}_{2} \mathrm{O}_{5}$ and $1.3 \mathrm{mM} \mathrm{Na} 2$ EDTA. The column used was an Aquasil C18 HPLC Column, 150 mm X 2.1 mm, $5 \mu$ m Particle Size (Thermo Electron, UK). Samples were quantified by comparison of the area under the curve against known external reference standards using a PC compatible HPLC software package (Chromatography Station for Windows ver.17 Data Apex Ltd). In addition to the assay of 5-HT and 5-HIAA tissue levels, the 5-HT turnover rate was also calculated, separately for each chromatograph as the ratio of 5HIAA/5-HT. Similarly, the ratios of DOPAC/DA and HVA/DA were calculated as an index of DA turnover rates. These turnover rates estimate the serotonergic and dopaminergic activities better than individual neurotransmitter and metabolite tissue levels as they reflect 5-HT and DA release and/or metabolic activity based on previous work (Bessinis et al., 2013; Dalla et al., 2008; Kokras et al., 2009; Mikail et al., 2012). All values were within 3 standard deviations of the overall mean. Unfortunately, monoamine analysis of one sample from the PFC (control+fluoxetine) and one sample from the hippocampus of another dam (control+stress) were not available due to technical error. Therefore group sizes were 4-6 for these animals with respect to monoamine levels. However, appropriate statistical power for significant monoamine findings were confirmed by partial eta-squared assessment.

Statistical Analysis. Analysis of variance tests (ANOVAs) were computed on synaptophysin density, PSD-95 density, Dnmt3-A density, DCX-ir cells, 5-HT, 5-HIAA, 5-HIAA/5-HT, DA, DOPAC, DOPAC/DA, HVA, HVA/DA, body weight, and litter characteristics with condition (stress/control) and treatment (fluoxetine/vehicle) as independent factors. Pearson productmoment correlations were run between density measures and monoamine levels. Posthoc comparisons were completed by Fisher LSD test for relevant interaction effects. Significance was set at $\mathrm{p}<0.05$. 


\section{RESULTS}

Body weight, litter weight and litter characteristics. At weaning dam weights were not significantly different $(\mathrm{p}=.06$; Control $=352.0 \pm 8.6 \mathrm{~g}$, Stress $=341.3 \pm 3.7 \mathrm{~g}$, Fluox $=357.3 \pm 6.1 \mathrm{~g}$, Stress+Fluox $=341.7 \pm 6.1 \mathrm{~g}$ ). There were no significant main effects or interaction between stress and treatment in dam weights on postpartum day 1 , litter weight and size on postpartum day 1 , or the number of male or female pups per litter.

Synaptophysin density. In the prefrontal areas, there was a significant condition by treatment effect on synaptophysin density in the $\mathrm{CG} 2$ area $(\mathrm{F}(1,18)=5.11, \mathrm{p}=.04$; Figure $2 \mathrm{~A})$, with posthoc test revealing that stress+vehicle females have a significantly higher density of synaptophysin compared to all other groups $(.003<\mathrm{p}<.04)$. There was also a significant main effect of stress in the $\mathrm{CG} 2$ area $(\mathrm{F}(1,18)=6.98, \mathrm{p}=0.02)$. There were no significant effects of gestational stress or fluoxetine treatment on synaptophysin density in the CG3, the IL or hippocampal areas (DG and CA3) investigated (Table 1).

PSD-95 density. There were no significant differences between groups in the density of PSD95ir cells in the brain areas investigated $(\mathrm{p}>.10$; Table 1$)$.

Dnmt3a density. There was a significant main effect of fluoxetine on Dnmt3a density in the DG area $(F(1,18)=5.49, p=.03$; Figure $2 B)$, with fluoxetine exposed females having decreased density of Dnmt3a. There were no significant differences in Dnmt3a reactivity in the hippocampal CA3 region or the investigated prefrontal cortex regions (Table 1) (p's >0.08).

DCX-ir cells in the dentate gyrus. There were no significant differences between groups in the number of DCX-ir cells in the number of hippocampal slices counted throughout the dentate gyrus of the maternal hippocampus ( $\mathrm{p}>.26$; data not shown).

Serotonergic system. In the PFC, there was a significant condition by treatment interaction in the ratio of $5-\mathrm{HIAA} / 5-\mathrm{HT}\left(\mathrm{F}(1,17)=9.96, \mathrm{p}=.006, \mathrm{\eta}_{\mathrm{p}}^{2}=.37\right.$; Figure $\left.3 \mathrm{~A}\right)$ with stress+vehicle females having a significantly higher ratio of 5-HIAA/5-HT than control+vehicle and stress+fluox females $(.007<\mathrm{p}<.009)$. 
In the hippocampus, there was a main effect of treatment on the ratio of 5-HIAA/5-HT $(\mathrm{F}(1$, $17)=5.20, p=.04, \eta_{p}^{2}=.23$; Figure $3 \mathrm{~B}$ ) with fluoxetine treated females (Fluox and Stress+Fluox) having a lower ratio. For 5-HIAA levels, there was a significant main effect of condition $(\mathrm{F}(1$, $17)=4.68, \mathrm{p}=.04)$ and treatment $(\mathrm{F}(1,17)=10.39, \mathrm{p}=.005)$ with females exposed to stress or fluoxetine having less 5-HIAA. There were no other significant differences between groups in serotonergic system measures investigated (Table 2). There were no significant correlations between measures of the serotonergic system and density measurements of PSD-95, synaptophysin, Dnmt3a ( $>0.1)$.

Dopaminergic system. There were no other significant differences between groups in measures of the dopaminergic system, in the PFC or hippocampus, investigated in the present study ( p's > .08 (Table 2).

\section{DISCUSSION}

With the increase in maternal stress-related disorders, such as depression, during the perinatal period and the increased use of SSRIs to treat maternal mood disorders, more research is needed to understand the effects of maternal stress, depression, and SSRI treatment on neurobiology in the maternal brain. Main findings from the present study show a differential effect of stress and SSRI treatment on synaptic plasticity, global cellular methylation and the serotonergic system in the PFC and hippocampus. In the PFC, gestational stress alone increased synaptophysin density in the CG2 area and serotonin metabolism, while fluoxetine treatment after stress normalized these effects. In the hippocampus, fluoxetine treatment, regardless of gestational stress exposure, decreased global cellular methylation levels in the dentate gyrus and decreased hippocampal serotonin metabolism. These findings demonstrate a brain region specific effect of gestational stress on the PFC and SSRI treatment on the hippocampus of the maternal brain. Furthermore these findings show that SSRI treatment can reverse some effects of stress in the mother.

\section{Gestational stress increases synaptophysin density in the PFC and these effects are} reversed by fluoxetine treatment. Results of the present study expand previous work which indicates plasticity changes during the peripartum period in the maternal brain, particularly in the 
hippocampus (for review see Pawluski et al 2015). Recent rodent work is also showing enduring effects of gestational stress on dendritic and spine complexity in other areas of the maternal circuit such as the amygdala, nucleus accumbens and the PFC (Haim et al., 2015; Haim et al., 2014; Leuner et al., 2014). Gestational stress increases spine density in the basolateral amygdala of rat dams, while reducing dendritic spine density in the nucleus accumbens shell and medial PFC (Haim et al., 2014). Additional work in the mPFC has shown that repeated gestational stress for two weeks during gestation can alter spine morphology and reduce spine density and PSD-95 immunoreactivity, a post synaptic marker, in rat dams during the post-partum period (Leuner et al., 2014). We found an increase in synaptophysin density, a presynaptic marker, in a similar region of the PFC as in Leuner et al (2014) at weaning in dams exposed to gestational stress during the last week of gestation. Discrepancies between our findings and those of previous work may be due to the difference in synaptic markers used. PSD-95 is a postsynaptic marker found on the majority of asymmetric neuronal synapses and can bind to AMPA receptors, NMDA receptors, and potassium channels where as synaptophysin is a presynaptic marker localized to neuroendocrine cells and virtually all neurons in the brain (Glantz et al., 2007). Therefore differences in the type of neurons and synapses these markers are present and may play a role in why we found an increase in synaptophysion density in the PFC after stress, where as others found a decrease in PSD-95 density in a similar area.

Interestingly, we found no effects of gestational stress or fluoxetine treatment on PSD-95 density in the brain regions investigated. As mentioned previously, one other study has shown a decrease in PSD-95 density in the mPFC in dams exposed to gestational stress (Leuner et al., 2014). Possible reasons for differences between our findings and that of previous work may be due to a number of methodological differences such as the duration and type of gestational stressor, behavioral testing during the early postpartum period, and/or the application of minipumps for SSRI administration. For example, Leuner et al used a 13 day gestational stressor, whereas the present work used a 7 days stressor. Duration of stress alone can have a significant impact on plasticity in the female brain (Pawluski et al., 2009a) and this work adds to a growing body of literature aimed at understanding the effect of various stress paradigms on the female hippocampus. Regardless of these differences, it can be concluded that gestational stress does affect markers of spine density in the maternal brain. 
We found that fluoxetine treatment to dams after gestational stress restored or normalized synaptophysin density in the CG2 region of the prefrontal cortex. This expands previous work showing that the SSRI citalopram can restore the gestational-stress induced deficits to structural plasticity, including reduced dendritic spine density on pyramidal neurons, in the medial prefrontal cortex of the maternal brain (Haim et al., 2015; Leuner et al., 2014). Such work suggests that maternal SSRI treatment may restore the effects of gestational stress and maternal depression, particularly on structural cortical plasticity, during the postpartum period.

Fluoxetine decreases methylation in the dentate gyrus of the maternal hippocampus. The present work shows a decrease in Dnmt3a, a marker of global cellular methylation, in the dentate gyrus of the hippocampus following fluoxetine treatment. While minimal work has investigated the role of antidepressant medications on methylation in the maternal brain, findings support previous work indicating decreased hippocampal methylation following fluoxetine treatment and DNA methylation inhibitor administration in male mice (Sales and Joca, 2015). Alternative SSRI medications, such as paroxetine and citalopram, have also been shown to reduce the Dnmt activity in adult rat primary cortical neurons (Zimmermann et al., 2012). In line with this, clinical work shows increased methylation of serotonin transporters in serum of SSRI treated depressed patients (Booij et al., 2015).

The decrease in Dnmt3a in the dentate gyrus may be related to the observed decrease in serotonin metabolism found in this region. Previous work has found decreased methylation of the MAO-A promoter region, an enzyme critical for serotonin metabolism, in whole blood serum of female patients with major depressive disorder (Domschke et al., 2015). This change in methylation was further associated with changes in antidepressant treatment response (Domschke et al., 2015). Fluoxetine may therefore play a similar role in altering methylation and serotonergic system functioning in the maternal hippocampus, a region critical for memory, stress, emotion, and mood regulation.

Previous literature has shown differential effects of stress on methylation, which was not found in the present study. Acute stress increases histone tri-methylation in the dentate gyrus and CA1 region of adult male rats while reducing histone mono-methylation in the same region (Hunter et al., 2009). Chronic stress however reduces histone tri-methylation in the dentate gyrus of adult male rats, which was reversed by fluoxetine treatment (Hunter et al., 2009). In addition, 
resilience to social defeat stress has been correlated to levels of Dnmt3a, which is further related to markers of neurogenesis in the hippocampus of adult male mice (Hammels et al., 2015). Lack of an effect of stress on measures in the current work may suggest a protective effect of motherhood on hippocampal methylation. This is not surprising as motherhood is associated with alterations in the stress response (Pawluski et al., 2009b; Slattery and Neumann, 2008) as well as changes in gene expression throughout numerous brain regions which are likely related to epigenetic and methylation mechanisms (Ray et al., 2015).

Furthermore we found no effect of fluoxetine treatment on the number of immature neurons in the dentate gyrus of the mother at the time of weaning. In line with this, recent work has shown that fluoxetine treatment can increase immature neurons in the dentate gyrus of nulliparous, but not postpartum female rats at postnatal day 23, approximately the same postnatal day as the current study (Workman et al., 2016). Previous work we have done shows that one week after weaning fluoxetine increased hippocampal neurogenesis in gestationally stressed dams (Pawluski et al., 2012a). This suggests that it may take a longer period of time for fluoxetine to affect hippocampal neurogenesis in the maternal brain or that that hormonal milieu of lactation and weaning may act to limit that effects of fluoxetine on hippocampal neurogenesis.

\section{Gestational stress and fluoxetine treatment alter serotonin levels in a brain region specific} manner in rat dams. Work from the present study shows that in the PFC gestational stress increased serotonin metabolism (5-HIAA/5-HT), and fluoxetine treatment after stress normalized this effect. In the hippocampus gestational stress did not have an effect on serotonin metabolism but fluoxetine, regardless of gestational stress exposure, decreased serotonin metabolism of the mother rat. To our knowledge this is the first work to investigate serotonin turnover in the maternal brain after gestational stress and in the presence of fluoxetine. These findings expand a growing body of literature investigating effects of stressors on serotonin levels and metabolites in the hippocampus and cortical areas. Recent findings in adult male mice show increased serotonin levels in the PFC after social isolation and restraint stress (Ago et al., 2013) and an increase in serotonin turnover (5-HIAA/5-HT) after exposure to aggressive interactions (Audet and Anisman, 2010). Although limited, work in female rats has shown increased 5-HT2A receptor mRNA levels in the orbitofrontal cortex and hippocampal CA4 region following four 
weeks of chronic mild stress, which is reversed after treatment with the antidepressant clomipramine (Pitychoutis et al., 2012).

Previous work has also shown alterations in serotonergic functioning after stress during pregnancy and in the post-partum period. Previous clinical work shows reduced tryptophan ratios and serotonin levels and increased SERT activity in blood samples of women reporting depressive-like symptoms in the post-partum period (Doornbos et al., 2008). Animal work has shown similar effects, with stress during pregnancy reducing 5-HT1A protein receptor levels in the prefrontal cortex and hippocampus of female rats (Szewczyk et al., 2014). Rhesus macaque mothers who demonstrate abusive mothering traits also show short allele variants of the serotonin transporter gene which is further associated with increased basal cortisol levels (McCormack et al., 2009). Therefore the effects of stress on serotonergic system functioning, seen in the present study, likely are related to the role of serotonin on maternal functioning and behavior.

We found that fluoxetine treatment after stress normalizes the effect of stress on serotonin levels in the prefrontal cortex of the maternal brain. This is perhaps not surprising as previous research shows that chronic escitalopram treatment upregulates serotonergic system functioning in the dorsal raphe and PFC in rats, suggesting appropriate regulation of serotonin following treatment (Yamada et al., 2013). Chronic fluoxetine treatment alters interneuron firing in the PFC and subsequently alters firing in brain regions critical for emotion such as the amygdala, making the PFC a suggested target for antidepressant therapies (Correll et al., 2005; Zhong and Yan, 2011). Taken together our findings suggest that fluoxetine treatment after stress may restore neuronal activity and subsequent serotonergic system functioning in the prefrontal cortex, a brain region critical for cognitive processing and coordination of complex thought and action, in the maternal brain.

In the hippocampus of rat dams we found that fluoxetine, regardless of gestational stress exposure, decreased serotonergic functioning. This work is in line with previous work showing that chronic fluoxetine administration to female rats reduces hippocampal 5-HIAA/5-HT ratios (McNamara et al., 2013) and that sub-chronic exposure to the SSRI sertraline decreases 5HIAA/5-HT levels in the hippocampus of male rats, regardless of stress exposure (Mikail et al., 
2012). These findings highlight that serotonergic metabolism of the hippocampus is particularly sensitive to SSRI treatment during adulthood.

\section{CONCLUSIONS}

Increased prevalence and duration of SSRI treatment during the perinatal period highlight the importance of investigations into the effects of these medications on the maternal brain. Work from the present study highlights brain region specific effects in the maternal brain with the prefrontal cortex being particularly sensitive to gestational stress, which can be normalized with SSRI treatment, and the hippocampus being particularly sensitive to the actions of SSRI medications; at least with reference to synaptophysin levels, methylation and serotonin metabolism. More work is needed to determine the behavioral correlates of these effects and how stress and SSRI medications may alter other brain regions important for maternal care and motherhood. 


\section{FIGURE LEGENDS}

Figure 1. Representative photomicrographs of A) DCX-ir cells in the granule cell layer $(G C L)$ B) synaptophysin-ir in the CA3 region C) PSD95-ir in the CA3 region and D) Dnmt3a-ir in the granule cell layer $(G C L)$ at $40 x$ objective. Scale bar is set at $25 \mu \mathrm{m}$.

Figure 2. A) Mean ( \pm SEM) synaptophysin density in the CG2 of the PFC. Stress+vehicle dams had a significantly higher density of synaptophysin compared to all other groups $(.003<\mathrm{p}<.04)$. There was also a significant main effect of stress in the CG2 area $(\mathrm{p}=.02)$. B) Mean $( \pm \mathrm{SEM})$ Dnmt3a density in the hippocampal DG region. There was a significant main effect of treatment with fluoxetine exposed females having reduced Dnmt3a density. ( $n=5-6 /$ group). *denotes significance

Figure 3. Mean $( \pm$ SEM) 5-HIAA/5-HT ratio in A) the PFC and B) the hippocampus. A) In the PFC, Stress females had significantly higher ratio of 5-HIAA/5-HT than Control and Stress+Fluox females $(.007<\mathrm{p}<.009)$. B) In the hippocampus, there was a main effect of treatment on the ratio of 5-HIAA/5-HT $(\mathrm{p}=.04)$ with fluoxetine treated females (Fluox and Stress+Fluox) having a lower ratio. (n=4-6/group). * denotes significance 
Table 1. Mean $( \pm$ SEM) density (OD) of synaptophysin, PSD-95 and Dnmt3a in additional areas of the hippocampus and PFC in dams. $\mathrm{CG}=$ cingulate cortex, $\mathrm{IL}=$ infralimbic area, $\mathrm{CA} 3=$ cornu ammonis 3, DG=dentate gyrus. There were no significant differences between groups. $\mathrm{n}=5$ 6/group.

\begin{tabular}{lrcccc}
\hline \multirow{2}{*}{ Synaptophysin } & Control & Stress & Fluox & Stress+Fluox \\
\cline { 3 - 6 } & IL & $0.50 \pm .01$ & $0.50 \pm .05$ & $0.52 \pm .02$ & $0.51 \pm .04$ \\
& CG3 & $0.38 \pm .01$ & $0.41 \pm .04$ & $0.39 \pm .04$ & $0.37 \pm .08$ \\
PSD-95 & CA3 & $0.17 \pm .02$ & $0.16 \pm .01$ & $0.15 \pm .02$ & $0.12 \pm .02$ \\
& DG & $0.18 \pm .03$ & $0.20 \pm .02$ & $0.22 \pm .01$ & $0.15 \pm .03$ \\
& & & & & \\
& IL & $0.15 \pm .03$ & $0.17 \pm .02$ & $0.14 \pm .01$ & $0.15 \pm .02$ \\
& CG2 & $0.11 \pm .02$ & $0.15 \pm .02$ & $0.10 \pm .01$ & $0.14 \pm .02$ \\
& CG3 & $0.10 \pm .02$ & $0.13 \pm .02$ & $0.11 \pm .02$ & $0.13 \pm .02$ \\
Dnmt3a & CA3 & $0.10 \pm .02$ & $0.12 \pm .02$ & $0.13 \pm .02$ & $0.12 \pm .02$ \\
& DG & $0.13 \pm .02$ & $0.16 \pm .03$ & $0.18 \pm .02$ & $0.17 \pm .02$ \\
& IL & $0.30 \pm .04$ & $0.39 \pm .04$ & $0.37 \pm .03$ & $0.38 \pm .04$ \\
& CG3 & $0.31 \pm .04$ & $0.39 \pm .05$ & $0.35 \pm .04$ & $0.38 \pm .02$ \\
& CG2 & $0.31 \pm .03$ & $0.39 \pm .03$ & $0.34 \pm .03$ & $0.35 \pm .03$ \\
& CA3 & $0.11 \pm .01$ & $0.13 \pm .05$ & $0.09 \pm .02$ & $0.10 \pm .02$ \\
\hline
\end{tabular}


Table 2. Mean $( \pm$ SEM) 5-HT levels $(\mu \mathrm{g} / \mathrm{g}), 5$-HIAA levels $(\mu \mathrm{g} / \mathrm{g})$, Dopamine levels (DA) $(\mu \mathrm{g} / \mathrm{g}), 3$,4-dihydroxyphenylacetic (DOPAC) acid levels $(\mu \mathrm{g} / \mathrm{g})$, homovanilic acid (HVA) levels $(\mu \mathrm{g} / \mathrm{g})$, DOPAC/DA ratios, HVA/DA ratios in the maternal PFC and hippocampus at weaning. In the hippocampus, there was a significant main effect of condition $(p=.04)$ and treatment $(p=.005)$ on 5-HIAA levels with females exposed to stress or fluoxetine having less hippocampal 5-HIAA. $\mathrm{n}=4-6 /$ group. * denotes significant effect of condition. ${ }^{@}$ denotes significant effect of treatment.

\begin{tabular}{lcccc}
\hline & Control & Stress & Fluox & Stress+Fluox \\
\cline { 2 - 5 }$\underline{\text { PFC }}$ & & & & \\
5-HT & $0.26 \pm 0.06$ & $0.22 \pm 0.15$ & $0.13 \pm 0.10$ & $0.26 \pm 0.06$ \\
5-HIAA & $0.31 \pm 0.03$ & $0.40 \pm 0.12$ & $0.28 \pm 0.02$ & $0.32 \pm 0.08$ \\
DA & $0.019 \pm 0.008$ & $0.019 \pm 0.01$ & $0.009 \pm 0.004$ & $0.016 \pm 0.002$ \\
DOPAC & $0.025 \pm 0.009$ & $0.018 \pm 0.002$ & $0.018 \pm 0.0002$ & $0.015 \pm 0.003$ \\
HVA & $0.030 \pm 0.015$ & $0.017 \pm 0.003$ & $0.018 \pm 0.002$ & $0.016 \pm 0.003$ \\
DOPAC/DA & $1.92 \pm .76$ & $2.49 \pm 1.00$ & $2.86 \pm .81$ & $0.92 \pm .16$ \\
HVA/DA & $1.74 \pm .52$ & $2.60 \pm 1.27$ & $1.03 \pm .17$ & $2.60 \pm 1.27$ \\
& & & & \\
Hippocampus & Control & Stress & Fluox & Stress+Fluox \\
5-HT & $0.13 \pm 0.03$ & $0.11 \pm 0.06$ & $0.19 \pm 0.01$ & $0.10 \pm 0.03$ \\
5-HIAA & $0.42 \pm 0.03$ & $0.33 \pm 0.04 *$ & $0.30 \pm 0.02$ & $0.25 \pm 0.04$ \\
DA & $0.010 \pm 0.002$ & $0.010 \pm 0.004$ & $0.012 \pm 0.003$ & $0.007 \pm 0.0008$ \\
DOPAC & $0.014 \pm 0.0006$ & $0.011 \pm 0.001$ & $0.013 \pm 0.002$ & $0.013 \pm 0.002$ \\
HVA & $0.004 \pm 0.0007$ & $0.004 \pm 0,0006$ & $0.005 \pm 0.0006$ & $0,007 \pm 0.003$ \\
DOPAC/DA & $1.74 \pm .33$ & $1.64 \pm .51$ & $1.32 \pm .36$ & $1.84 \pm .27$ \\
HVA/DA & $0.51 \pm .09$ & $0.47 \pm .09$ & $0.51 \pm .10$ & $0.94 \pm .30$ \\
\hline
\end{tabular}




\section{REFERENCES}

Ago Y, Araki R, Tanaka T, Sasaga A, Nishiyama S, Takuma K, Matsuda T (2013), Role of social encounter-induced activation of prefrontal serotonergic systems in the abnormal behaviors of isolation-reared mice. Neuropsychopharmacology 38: 1535-1547.

Andersen SL, Teicher MH (1999), Serotonin laterality in amygdala predicts performance in the elevated plus maze in rats. Neuroreport 10: 3497-3500.

Angoa-Perez M, Kane MJ, Sykes CE, Perrine SA, Church MW, Kuhn DM (2014), Brain serotonin determines maternal behavior and offspring survival. Genes Brain Behav 13: 579-591.

Audet MC, Anisman H (2010), Neuroendocrine and neurochemical impact of aggressive social interactions in submissive and dominant mice: implications for stress-related disorders. Int $\mathbf{J}$ Neuropsychopharmacol 13: 361-372.

Barden N, Reul JM, Holsboer F (1995), Do antidepressants stabilize mood through actions on the hypothalamic-pituitary-adrenocortical system? Trends Neurosci 18: 6-11.

Bennett HA, Einarson A, Taddio A, Koren G, Einarson TR (2004), Prevalence of depression during pregnancy: systematic review. Obstet Gynecol 103: 698-709.

Bessinis DP, Dalla C, Kokras N, Pitychoutis PM, Papadopoulou-Daifoti Z (2013), Sex-dependent neurochemical effects of environmental enrichment in the visual system. Neuroscience 254: 130140.

Beversdorf DQ, Manning SE, Hillier A, Anderson SL, Nordgren RE, Walters SE, Nagaraja HN, Cooley WC, Gaelic SE, Bauman ML (2005), Timing of prenatal stressors and autism. J Autism Dev Disord 35: 471-478.

Booij L, Szyf M, Carballedo A, Frey EM, Morris D, Dymov S, Vaisheva F, Ly V, Fahey C, Meaney J, Gill M, Frodl T (2015), DNA methylation of the serotonin transporter gene in peripheral cells and stress-related changes in hippocampal volume: a study in depressed patients and healthy controls. PLoS One 10: e0119061.

Brummelte S, Galea LA (2010), Chronic corticosterone during pregnancy and postpartum affects maternal care, cell proliferation and depressive-like behavior in the dam. Horm Behav 58: 769779.

Cooper WO, Willy ME, Pont SJ, Ray WA (2007), Increasing use of antidepressants in pregnancy. Am J Obstet Gynecol 196: 544 e541-545.

Correll CM, Rosenkranz JA, Grace AA (2005), Chronic cold stress alters prefrontal cortical modulation of amygdala neuronal activity in rats. Biol Psychiatry 58: 382-391.

Curry T, Egeto P, Wang H, Podnos A, Wasserman D, Yeomans J (2013), Dopamine receptor D2 deficiency reduces mouse pup ultrasonic vocalizations and maternal responsiveness. Genes Brain Behav 12: 397-404.

Dalla C, Antoniou K, Kokras N, Drossopoulou G, Papathanasiou G, Bekris S, Daskas S, PapadopoulouDaifoti Z (2008), Sex differences in the effects of two stress paradigms on dopaminergic neurotransmission. Physiol Behav 93: 595-605.

Darnaudery M, Dutriez I, Viltart O, Morley-Fletcher S, Maccari S (2004), Stress during gestation induces lasting effects on emotional reactivity of the dam rat. Behav Brain Res 153: 211-216.

Darnaudery M, Maccari S (2008), Epigenetic programming of the stress response in male and female rats by prenatal restraint stress. Brain Res Rev 57: 571-585.

Davies P, Cicchetti D, Hentges RF (2015), Maternal unresponsiveness and child disruptive problems: the interplay of uninhibited temperament and dopamine transporter genes. Child Dev 86: 63-79.

Domschke K, Tidow N, Schwarte K, Ziegler C, Lesch KP, Deckert J, Arolt V, Zwanzger P, Baune BT (2015), Pharmacoepigenetics of depression: no major influence of MAO-A DNA methylation on treatment response. J Neural Transm (Vienna) 122: 99-108.

Doornbos B, Fekkes D, Tanke MA, de Jonge P, Korf J (2008), Sequential serotonin and noradrenalin associated processes involved in postpartum blues. Prog Neuropsychopharmacol Biol Psychiatry 32: $1320-1325$. 
Fleschler R, Peskin M, F. (2007), Selective serotonin reuptake inhibitors (SSRIs) in pregnancy: a review. MCN The American journal of maternal child nursing 33: 355.

Gemmel M, Rayen I, Lotus T, van Donkelaar E, Steinbusch HW, De Lacalle S, Kokras N, Dalla C, Pawluski JL (2015), Developmental fluoxetine and prenatal stress effects on serotonin, dopamine, and synaptophysin density in the PFC and hippocampus of offspring at weaning. Dev Psychobiol.

Glantz LA, Gilmore JH, Hamer RM, Lieberman JA, Jarskog LF (2007), Synaptophysin and postsynaptic density protein 95 in the human prefrontal cortex from mid-gestation into early adulthood. Neuroscience 149: 582-591.

Glover V, O'Connor TG, O'Donnell K (2009), Prenatal stress and the programming of the HPA axis. Neurosci Biobehav Rev.

Haim A, Albin-Brooks C, Sherer M, Mills E, Leuner B (2015), The effects of gestational stress and SSRI antidepressant treatment on structural plasticity in the postpartum brain - A translational model for postpartum depression. Horm Behav.

Haim A, Sherer M, Leuner B (2014), Gestational stress induces persistent depressive-like behavior and structural modifications within the postpartum nucleus accumbens. Eur J Neurosci 40: 37663773.

Hammels C, Prickaerts J, Kenis G, Vanmierlo T, Fischer M, Steinbusch HW, van Os J, van den Hove DL, Rutten BP (2015), Differential susceptibility to chronic social defeat stress relates to the number of Dnmt3a-immunoreactive neurons in the hippocampal dentate gyrus. Psychoneuroendocrinology 51: 547-556.

Hillerer KM, Neumann ID, Couillard-Despres S, Aigner L, Slattery DA (2014), Lactation-induced reduction in hippocampal neurogenesis is reversed by repeated stress exposure. Hippocampus 24: 673-683.

Hillerer KM, Reber SO, Neumann ID, Slattery DA (2011), Exposure to chronic pregnancy stress reverses peripartum-associated adaptations: implications for postpartum anxiety and mood disorders. Endocrinology 152: 3930-3940.

Huang Y, Chen S, Xu H, Yu X, Lai H, Ho G, Huang Q, Shi X (2013), Pre-gestational stress alters stressresponse of pubertal offspring rat in sexually dimorphic and hemispherically asymmetric manner. BMC Neurosci 14: 67.

Huang Y, Shi X, Xu H, Yang H, Chen T, Chen S, Chen X (2010), Chronic unpredictable stress before pregnancy reduce the expression of brain-derived neurotrophic factor and N-methyl-D-aspartate receptor in hippocampus of offspring rats associated with impairment of memory. Neurochem Res 35: 1038-1049.

Huang Y, Xu H, Li H, Yang H, Chen Y, Shi X (2012), Pre-gestational stress reduces the ratio of 5-HIAA to 5-HT and the expression of 5-HT1A receptor and serotonin transporter in the brain of foetal rat. BMC Neurosci 13: 22.

Huizink AC, Mulder EJ, Buitelaar JK (2004), Prenatal stress and risk for psychopathology: specific effects or induction of general susceptibility? Psychol Bull 130: 115-142.

Huizink AC, Robles de Medina PG, Mulder EJ, Visser GH, Buitelaar JK (2003), Stress during pregnancy is associated with developmental outcome in infancy. J Child Psychol Psychiatry 44: 810-818.

Hunter RG, McCarthy KJ, Milne TA, Pfaff DW, McEwen BS (2009), Regulation of hippocampal H3 histone methylation by acute and chronic stress. Proc Natl Acad Sci U S A 106: 20912-20917.

Keer SE, Stern JM (1999), Dopamine receptor blockade in the nucleus accumbens inhibits maternal retrieval and licking, but enhances nursing behavior in lactating rats. Physiol Behav 67: 659-669.

Kohl C, Walch T, Huber R, Kemmler G, Neurauter G, Fuchs D, Solder E, Schrocksnadel H, SpernerUnterweger B (2005), Measurement of tryptophan, kynurenine and neopterin in women with and without postpartum blues. J Affect Disord 86: 135-142.

Kokras N, Antoniou K, Dalla C, Bekris S, Xagoraris M, Ovestreet DH, Papadopoulou-Daifoti Z (2009), Sex-related differential response to clomipramine treatment in a rat model of depression. $\mathrm{J}$ Psychopharmacol 23: 945-956. 
Kyratsas C, Dalla C, Anderzhanova E, Polissidis A, Kokras N, Konstantinides K, Papadopoulou-Daifoti Z (2013), Experimental evidence for sildenafil's action in the central nervous system: dopamine and serotonin changes in the medial preoptic area and nucleus accumbens during sexual arousal. The journal of sexual medicine 10: 719-729.

Lancaster CA, Gold KJ, Flynn HA, Yoo H, Marcus SM, Davis MM (2010), Risk factors for depressive symptoms during pregnancy: a systematic review. Am J Obstet Gynecol 202: 5-14.

Laplante DP, Barr RG, Brunet A, Galbaud du Fort G, Meaney ML, Saucier JF, Zelazo PR, King S (2004), Stress during pregnancy affects general intellectual and language functioning in human toddlers. Pediatr Res 56: 400-410.

Lemaire V, Billard JM, Dutar P, George O, Piazza PV, Epelbaum J, Le Moal M, Mayo W (2006), Motherhood-induced memory improvement persists across lifespan in rats but is abolished by a gestational stress. Eur J Neurosci 23: 3368-3374.

Leuner B, Fredericks PJ, Nealer C, Albin-Brooks C (2014), Chronic gestational stress leads to depressivelike behavior and compromises medial prefrontal cortex structure and function during the postpartum period. PLoS One 9: e89912.

Maccari S, Morley-Fletcher S (2007), Effects of prenatal restraint stress on the hypothalamus-pituitaryadrenal axis and related behavioural and neurobiological alterations. Psychoneuroendocrinology 32 Suppl 1: S10-15.

Maghsoudi N, Ghasemi R, Ghaempanah Z, Ardekani AM, Nooshinfar E, Tahzibi A (2014), Effect of Chronic Restraint Stress on HPA Axis Activity and Expression of BDNF and Trkb in the Hippocampus of Pregnant Rats: Possible Contribution in Depression during Pregnancy and Postpartum Period. Basic Clin Neurosci 5: 131-137.

Malberg JE, Duman RS (2003), Cell proliferation in adult hippocampus is decreased by inescapable stress: reversal by fluoxetine treatment. Neuropsychopharmacology 28: 1562-1571.

McCormack K, Newman TK, Higley JD, Maestripieri D, Sanchez MM (2009), Serotonin transporter gene variation, infant abuse, and responsiveness to stress in rhesus macaque mothers and infants. Horm Behav 55: 538-547.

McNamara RK, Able JA, Liu Y, Jandacek R, Rider T, Tso P, Lipton JW (2013), Omega-3 fatty acid deficiency does not alter the effects of chronic fluoxetine treatment on central serotonin turnover or behavior in the forced swim test in female rats. Pharmacol Biochem Behav 114-115: 1-8.

Mikail HG, Dalla C, Kokras N, Kafetzopoulos V, Papadopoulou-Daifoti Z (2012), Sertraline behavioral response associates closer and dose-dependently with cortical rather than hippocampal serotonergic activity in the rat forced swim stress. Physiol Behav 107: 201-206.

Mitchell AA, Gilboa SM, Werler MM, Kelley KE, Louik C, Hernandez-Diaz S, National Birth Defects Prevention S (2011), Medication use during pregnancy, with particular focus on prescription drugs: 1976-2008. Am J Obstet Gynecol 205: 51 e51-58.

Molodtsova GF (2001), [Effects of sex factors and hemispheric localization on the involvement of serotonin from the frontal cortex, striatum, and nucleus accumbens into the processing of novel and repeatedly presented information in rats]. Zh Vyssh Nerv Deiat Im I P Pavlova 51: 56-60.

Moses-Kolko EL, Horner MS, Phillips ML, Hipwell AE, Swain JE (2014), In search of neural endophenotypes of postpartum psychopathology and disrupted maternal caregiving. $\mathrm{J}$ Neuroendocrinol 26: 665-684.

Niederhofer H, Reiter A (2004), Prenatal maternal stress, prenatal fetal movements and perinatal temperament factors influence behavior and school marks at the age of 6 years. Fetal Diagn Ther 19: $160-162$.

O'Mahony SM, Myint AM, van den Hove D, Desbonnet L, Steinbusch H, Leonard BE (2006), Gestational stress leads to depressive-like behavioural and immunological changes in the rat. Neuroimmunomodulation 13: 82-88.

Oberlander TF, Gingrich JA, Ansorge MS (2009), Sustained neurobehavioral effects of exposure to SSRI antidepressants during development: molecular to clinical evidence. Clin Pharmacol Ther 86: 672-677. 
Pawluski JL, Brummelte S, Barha CK, Crozier TM, Galea LA (2009a), Effects of steroid hormones on neurogenesis in the hippocampus of the adult female rodent during the estrous cycle, pregnancy, lactation and aging. Front Neuroendocrinol 30: 343-357.

Pawluski JL, Charlier TD, Fillet M, Houbart V, Crispin HT, Steinbusch HW, van den Hove DL (2012a), Chronic fluoxetine treatment and maternal adversity differentially alter neurobehavioral outcomes in the rat dam. Behav Brain Res 228: 159-168.

Pawluski JL, Charlier TD, Lieblich SE, Hammond GL, Galea LA (2009b), Reproductive experience alters corticosterone and CBG levels in the rat dam. Physiol Behav 96: 108-114.

Pawluski JL, Csaszar E, Savage E, Martinez-Claros M, Steinbusch HW, van den Hove D (2015), Effects of stress early in gestation on hippocampal neurogenesis and glucocorticoid receptor density in pregnant rats. Neuroscience 290: 379-388.

Pawluski JL, Rayen I, Niessen NA, Kristensen S, van Donkelaar EL, Balthazart J, Steinbusch HW, Charlier TD (2012b), Developmental fluoxetine exposure differentially alters central and peripheral measures of the HPA system in adolescent male and female offspring. Neuroscience 220: 131-141.

Pawluski JL, Valenca A, Santos AI, Costa-Nunes JP, Steinbusch HW, Strekalova T (2012c), Pregnancy or stress decrease complexity of CA3 pyramidal neurons in the hippocampus of adult female rats. Neuroscience 227: 201-210.

Pawluski JL, van den Hove DL, Rayen I, Prickaerts J, Steinbusch HW (2011), Stress and the pregnant female: Impact on hippocampal cell proliferation, but not affective-like behaviors. Horm Behav 59: $572-580$.

Pawluski JL, van Donkelaar E, Abrams Z, Houbart V, Fillet M, Steinbusch HW, Charlier TD (2014), Fluoxetine dose and administration method differentially affect hippocampal plasticity in adult female rats. Neural Plast 2014: 123026.

Pitychoutis PM, Dalla C, Sideris AC, Tsonis PA, Papadopoulou-Daifoti Z (2012), 5-HT(1A), 5-HT(2A), and 5-HT(2C) receptor mRNA modulation by antidepressant treatment in the chronic mild stress model of depression: sex differences exposed. Neuroscience 210: 152-167.

Ray S, Tzeng RY, DiCarlo LM, Bundy JL, Vied C, Tyson G, Nowakowski R, Arbeitman MN (2015), An Examination of Dynamic Gene Expression Changes in the Mouse Brain During Pregnancy and the Postpartum Period. G3 (Bethesda) 6: 221-233.

Rayen I, Gemmel M, Pauley G, Steinbusch HW, Pawluski JL (2015), Developmental exposure to SSRIs, in addition to maternal stress, has long-term sex-dependent effects on hippocampal plasticity. Psychopharmacology 232: 1231-1244.

Rayen I, Steinbusch HW, Charlier TD, Pawluski JL (2013), Developmental fluoxetine exposure and prenatal stress alter sexual differentiation of the brain and reproductive behavior in male rat offspring. Psychoneuroendocrinology.

Rayen I, Steinbusch HW, Charlier TD, Pawluski JL (2014), Developmental fluoxetine exposure facilitates sexual behavior in female offspring. Psychopharmacology (Berl) 231: 123-133.

Rayen I, van den Hove DL, Prickaerts J, Steinbusch HW, Pawluski JL (2011), Fluoxetine during development reverses the effects of prenatal stress on depressive-like behavior and hippocampal neurogenesis in adolescence. PLoS One 6: e24003.

Sales AJ, Joca SR (2015), Effects of DNA methylation inhibitors and conventional antidepressants on mice behaviour and brain DNA methylation levels. Acta Neuropsychiatr 1-12.

Santarelli L, Saxe M, Gross C, Surget A, Battaglia F, Dulawa S, Weisstaub N, Lee J, Duman R, Arancio O, Belzung C, Hen R (2003), Requirement of hippocampal neurogenesis for the behavioral effects of antidepressants. Science 301: 805-809.

Slattery DA, Neumann ID (2008), No stress please! Mechanisms of stress hyporesponsiveness of the maternal brain. J Physiol 586: 377-385.

Smith JW, Seckl JR, Evans AT, Costall B, Smythe JW (2004), Gestational stress induces post-partum depression-like behaviour and alters maternal care in rats. Psychoneuroendocrinology 29: 227244. 
Stamatakis A, Kalpachidou T, Raftogianni A, Zografou E, Tzanou A, Pondiki S, Stylianopoulou F (2015), Rat dams exposed repeatedly to a daily brief separation from the pups exhibit increased maternal behavior, decreased anxiety and altered levels of receptors for estrogens (ERalpha, ERbeta), oxytocin and serotonin (5-HT1A) in their brain. Psychoneuroendocrinology 52: 212228.

Stewart DE (2011), Clinical practice. Depression during pregnancy. N Engl J Med 365: 1605-1611.

Szewczyk B, Kotarska K, Daigle M, Misztak P, Sowa-Kucma M, Rafalo A, Curzytek K, Kubera M, Basta-Kaim A, Nowak G, Albert PR (2014), Stress-induced alterations in 5-HT1A receptor transcriptional modulators NUDR and Freud-1. Int J Neuropsychopharmacol 17: 1763-1775.

Talge NM, Neal C, Glover V, Early Stress TR, Prevention Science Network F, Neonatal Experience on C, Adolescent Mental H (2007), Antenatal maternal stress and long-term effects on child neurodevelopment: how and why? J Child Psychol Psychiatry 48: 245-261.

Van den Bergh BR, Mennes M, Oosterlaan J, Stevens V, Stiers P, Marcoen A, Lagae L (2005), High antenatal maternal anxiety is related to impulsivity during performance on cognitive tasks in 14and 15-year-olds. Neurosci Biobehav Rev 29: 259-269.

Van den Bergh BR, Van Calster B, Smits T, Van Huffel S, Lagae L (2008), Antenatal maternal anxiety is related to HPA-axis dysregulation and self-reported depressive symptoms in adolescence: a prospective study on the fetal origins of depressed mood. Neuropsychopharmacology 33: 536545.

Van den Hove DL, Blanco CE, Aendekerk B, Desbonnet L, Bruschettini M, Steinbusch HP, Prickaerts J, Steinbusch HW (2005), Prenatal restraint stress and long-term affective consequences. Dev Neurosci 27: 313-320.

Veen C, Myint AM, Burgerhout KM, Schwarz MJ, Schutze G, Kushner SA, Hoogendijk WJ, Drexhage HA, Bergink V (2016), Tryptophan pathway alterations in the postpartum period and in acute postpartum psychosis and depression. J Affect Disord 189: 298-305.

Ververs T, Kaasenbrood H, Visser G, Schobben F, de Jong-van den Berg L, Egberts T (2006), Prevalence and patterns of antidepressant drug use during pregnancy. Eur J Clin Pharmacol 62: 863-870.

Vicentic A, Francis D, Moffett M, Lakatos A, Rogge G, Hubert GW, Harley J, Kuhar MJ (2006), Maternal separation alters serotonergic transporter densities and serotonergic $1 \mathrm{~A}$ receptors in rat brain. Neuroscience 140: 355-365.

Weinstock M (2007), Gender differences in the effects of prenatal stress on brain development and behaviour. Neurochem Res 32: 1730-1740.

Workman JL, Brummelte S, Galea LA (2013), Postpartum corticosterone administration reduces dendritic complexity and increases the density of mushroom spines of hippocampal CA3 arbours in dams. J Neuroendocrinol 25: 119-130.

Workman JL, Gobinath AR, Kitay NF, Chow C, Brummelte S, Galea LA (2016), Parity modifies the effects of fluoxetine and corticosterone on behavior, stress response and hippocampal neurogenesis. Neuropharmacology.

Yamada M, Kawahara Y, Kaneko F, Kishikawa Y, Sotogaku N, Poppinga WJ, Folgering JH, Dremencov E, Kawahara H, Nishi A (2013), Upregulation of the dorsal raphe nucleus-prefrontal cortex serotonin system by chronic treatment with escitalopram in hyposerotonergic Wistar-Kyoto rats. Neuropharmacology 72: 169-178.

Zhong P, Yan Z (2011), Differential regulation of the excitability of prefrontal cortical fast-spiking interneurons and pyramidal neurons by serotonin and fluoxetine. PLoS One 6: e16970.

Zimmermann N, Zschocke J, Perisic T, Yu S, Holsboer F, Rein T (2012), Antidepressants inhibit DNA methyltransferase 1 through reducing G9a levels. Biochem J 448: 93-102. 
Figure 1
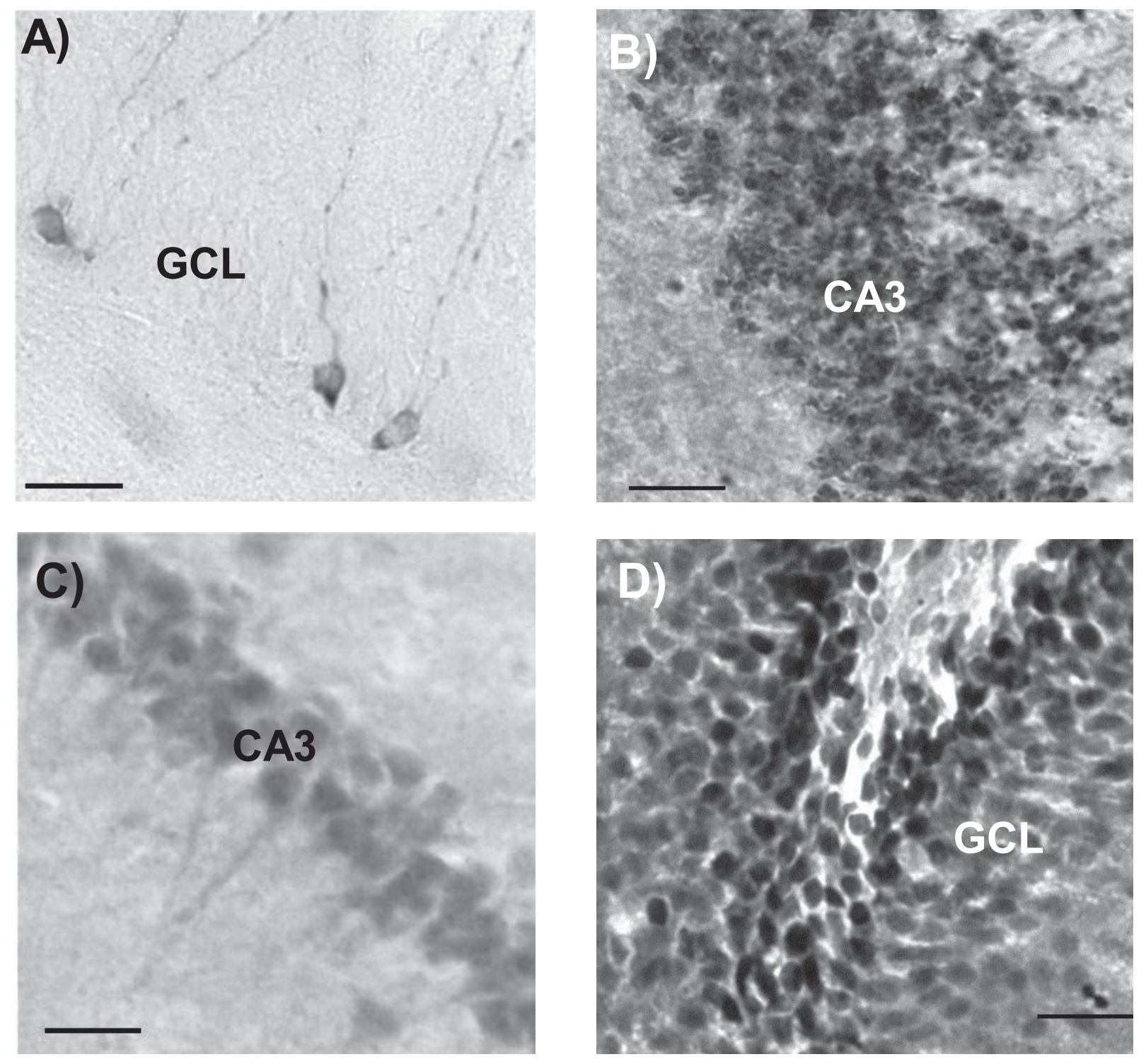
Figure 2
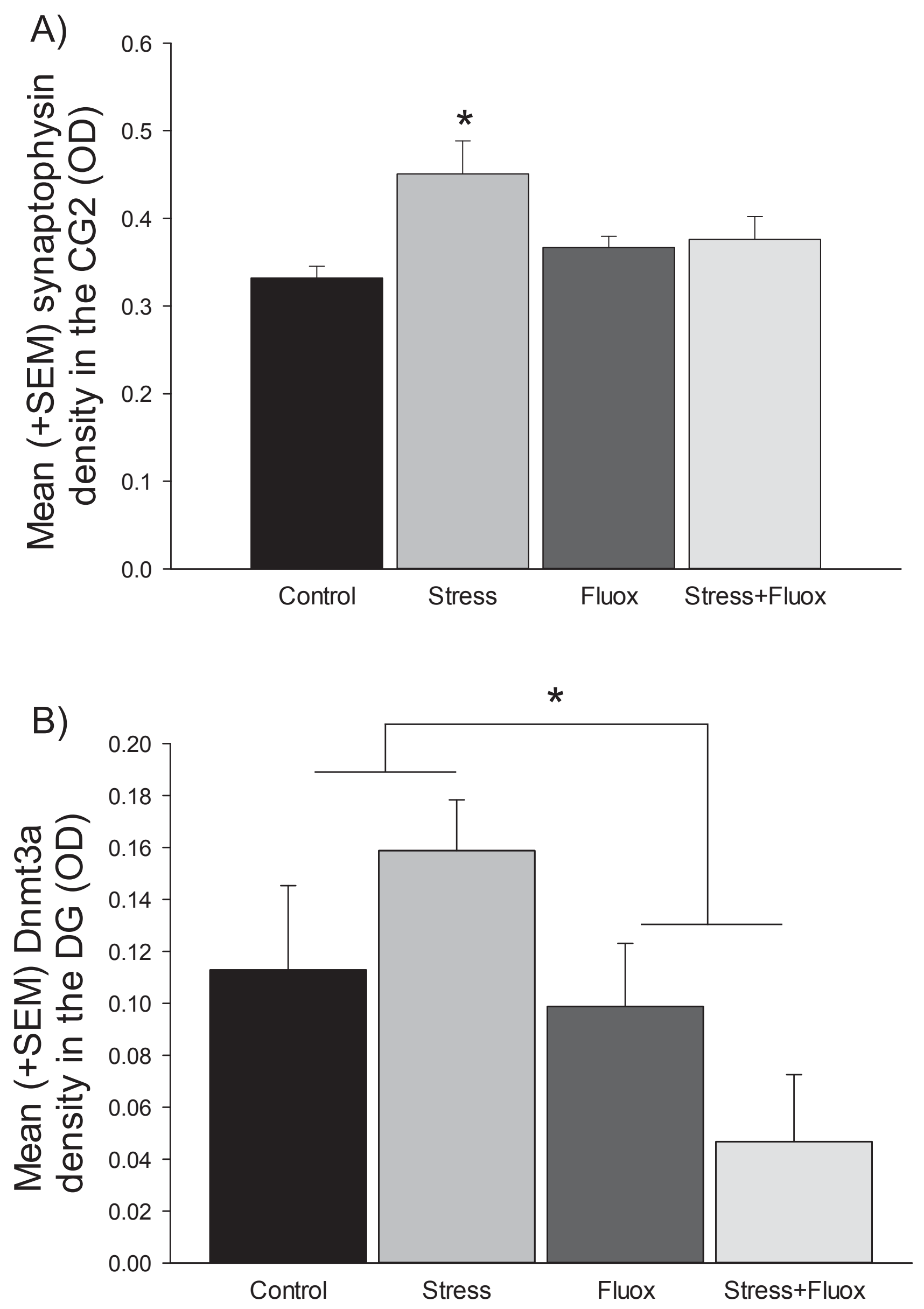
Figure 3
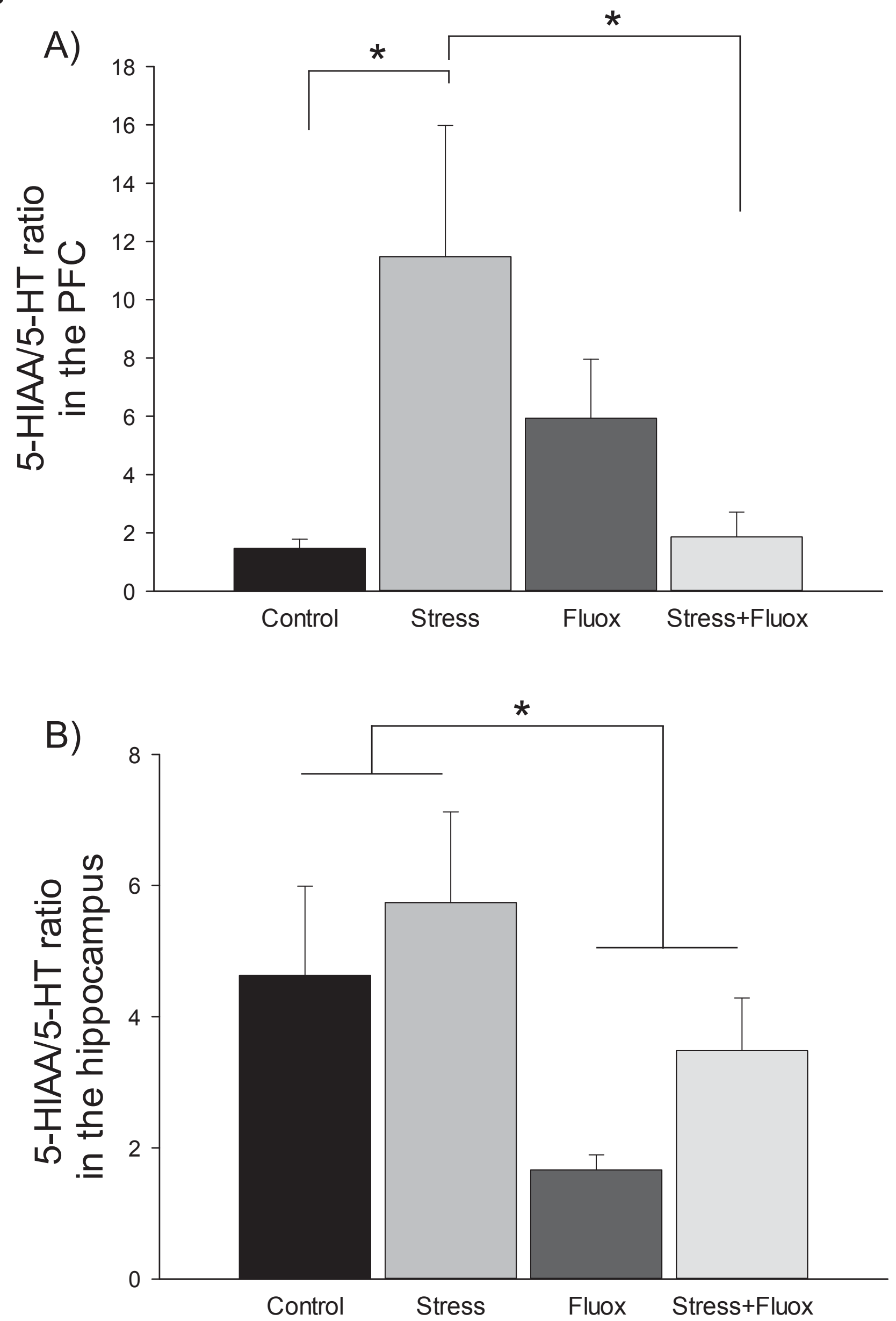


\section{Highlights}

Gestational stress and fluoxetine affect the maternal brain in a region-specific manner

Stress during gestation increases synaptophysin and serotonin in the PFC, but not hippocampus

Fluoxetine reverses the effect of gestational stress on the maternal PFC

Fluoxetine during lactation decreases methylation and serotonin in the maternal hippocampus 